\title{
Introduction of a New Cycle in Replacement of Metonic: An Ideal Solution towards a Deviation Free Luni-Solar Calendar
}

\author{
A. K. M. Amirul Islam \\ Independent Researcher, Rajshahi, Bangladesh \\ Email: bcs13.amirul@gmail.com
}

How to cite this paper: Amirul Islam, A.K.M. (2021) Introduction of a New Cycle in Replacement of Metonic: An Ideal Solution towards a Deviation Free Luni-Solar Calendar. Open Journal of Applied Sciences, 11, 1060-1070.

https://doi.org/10.4236/ojapps.2021.119078

Received: August 11, 2021

Accepted: September 26, 2021

Published: September 29, 2021

Copyright $\odot 2021$ by author(s) and Scientific Research Publishing Inc. This work is licensed under the Creative Commons Attribution International License (CC BY 4.0).

http://creativecommons.org/licenses/by/4.0/

\begin{abstract}
Molad is simply an interval between two successive new moon timelines with respect to the line joining the Sun and the Earth i.e., with respect to the Sun as seen from the Earth, which in scientific terms is referred as lunation or "synodic lunar month". Though synodic lunar month may vary by up to \pm 0.7 days locally, the length of mean synodic lunar month is constant over a long period of time and is a crucial value in determining the luni-solar calendar's new months similar to Hebrew calendar's "Rashei Hodesh". Based on the Metonic cycle the luni-solar Hebrew calendar adds 07 intercalary months in 19 solar years. This hypothesis proposes a new cycle instead of the Metonic cycle towards eliminating the deviation of the calendar incurred in the long course of time. The research analyzed that application of the conventional Metonic cycle to luni-solar calendar is erroneous, which theoretically leads Hebrew calendar to absorb extra 11 days (approx.) by 2053 years after inception. The study pointed out that through the application of 2116 - 2053 lunar-solar years cycle instead of 235 228 lunar-solar months based Metonic cycle, formulation of a far better high precession luni-solar calendar is possible and also both lunar and solar sides of the luni-solar calendar became fully balanced and harmonized.
\end{abstract}

\section{Keywords}

Luni-Solar Calendar, Hebrew Calendar, Molad, Metonic Cycle, Intercalary Month, Synodic Lunar Month, Tropical Solar Year, NASA, LRO

\section{Introduction}

The Jewish calendar was laid out by Rabbi Hillel II in the year 4119 (358 - 359 C.E.), which was finally consolidated and fully described by Rabbi Maimonides around the year $1178 \mathrm{CE}$. The Hebrew calendar starts counting years from 3761 BCE and it uses a cycle called "Metonic Cycle" for calculation. Recent observa- 
tion reveals that this calendar in use now may have slowly drifted off track as also illustrated in an article of "Your Jerusalem" [1]. For the year 2000, the length of the mean synodic lunar month (Molad) is expressed as 29.530588 days in Astropixel's Six Millennium Catalog of Phases of the Moon [2]. The article also maintained the same astronomical value, which is 0.5184 second shorter than the Hebrew calendar Molad, though the article was merely an updated reprint of an original article published in 1999 CE. Mind that Metonic cycle was also known in China by about $600 \mathrm{BCE}$ and was called the Zhang cycle and before 621 BCE, the start of new month was based solely on visibility of the crescent Moon [3]. It is stated that the Hebrew calendar's mean lunar month duration discrepancy from current astronomical value amounts to only one day in 14,000 years [4]. But I am with a view to revisit the astronomical value of the length of the lunar year having a value of $29.530588 \times 12=354.367056$ days too. Because, when this astronomical value and/or the Hebrew Molad is used to calculate the length of "Tropical Solar Year" using the Metonic cycle, a significant deviation is observed with the well established latest astronomical value i.e. 365.24219 days, as shown below:

Let us use the Hebrew Molad for the calculation,

Mean Tropical Solar Year $=\frac{29.5305941358 \times 12 \times 235}{228}=365.2468222059$ days .

It is noticed that throughout the history various attempts were also made by different scholars for modification/adjustment of the 19-year long Metonic cycle as below:

- The cycle of $76(4 \times 19)$ years is the improvement of the Metonian cycle by Greek astronomer Callippus of Cyzicus (about 330 BCE).

- The cycle of $95(5 \times 19)$ years had been used by Alexandrian bishops Theophilus and St. Cyrillus (c. 376 - $444 \mathrm{CE}$ ) for the computation of Easter.

- The cycle of $532(28 \times 19)$ years was invented by the Pope Anianus of Alexandria (about $61 \mathrm{CE}$ ) [5].

Thus, hereby an inference could be drawn regarding the Hebrew calendar that it has been suffering from harmonization problem in between lunar and solar sides simultaneously. So, high precession value for both sides could not be attained at the same time, which raised the scope of calendar-reform through adjustment/fine tuning of the Metonic cycle.

With a lunar or luni-solar calendar, errors are much more obvious than with a solar calendar. A solar calendar can be off by a couple of weeks without anybody noticing. But with a lunar calendar, an error of even a couple of days is a serious problem. Every peasant could each month see that the new Moon was visible near the end of the previous month or that the old Moon was visible in the next month [3]. For the purpose of settlement of religious festival dates, this is a more serious issue too. For example, Passover must occur in spring, which is a solar phenomenon in contrary to the fact that the Hebrew calendar months are lunar [4]. Again Easter Sunday is the first Sunday after the first full Moon on or after the day of the March equinox (falls between March 22 and April 25), which is 
also a solar event [3]. That is why a luni-solar calendar like Hebrew calendar is more or less complex in nature, synchronization with both lunar and solar cycles with a high degree of perfection is required here. So in this critical arena of luni-solar calendar an ideal and more unified approach toward a sophisticated calendar reform is a necessity. In this context, to my consideration, the conversion cycle in use (Metonic Cycle) plays here a pivotal role and should be revisited. Thus, through this research the problem and scope of replacement of the Metonic cycle is analyzed and a new cycle is proposed so that inconsistencies persisted with luni-solar calendars like the Hebrew calendar are eventually minimized.

It is commonly thought that a little bit lesser value of Molad might be the possible solution to the problem of complete harmonization between the lunar and solar sides of the Hebrew calendar [1]. Based upon nearly 08 years (100 lunar months) close observation of NASA's Lunar Reconnaissance Orbiter (LRO) of the Moon "NASA Goddard media" studio has released a video on Oct. 06, 2017 named "100 lunar days-Part I and II". The media narrated the mean synodic lunar month as 29.5306 as below. However, fourth decimal digit "6" may be due to rounding up effect, which is not clear here?

" A mean solar day on the Moon, a lunar day for short, is 29.5306 Earth days. Local lunar days can vary even more than solar days on Earth, over 6 hours shorter or 7 hours longer than the mean. The 100 lunar days celebrated by LRO in October of 2017 are mean lunar days." [6]

\section{Molad of Hebrew Calendar}

"Molad" means birth (of a new moon) and lunation or synodic lunar month means interval between two successive molads, though for simplicity synodic lunar month is often referred to as "Molad".

Calculation of Hebrew calendar's Molad:

Hebrew calendar maintains,

01 Lunar month $=29$ days +12 hours +793 halaqim

Hour is divided into 1080 parts called halaqim ( 1 halaqim $=3 \frac{1}{3}$ seconds)

Hebrew calendar was devised according to Metonic cycle, 19 solar years $=235$ lunar months and it is thought that the Babylonians first applied the 19-year cycle in their calendar in the late sixth century BCE. The month names of the Hebrew calendar were also derived from the Babylonian calendar dating back to the 6th Century BC during the Babylonian exile.

Therefore, 228 solar months (19 solar years) $=235$ lunar years

Thus, Hebrew calendar Molad $=29.5+\frac{793 \times 10}{3 \times 3600 \times 24}=29.5305941358$ days

The length of Hebrew calendar lunar year $=29.5305941358$ days $\times 12$

$$
=354.36712963 \text { days }
$$

Considering the Metonic cycle, from Molad we have the length of solar year 
as- $=\frac{235 \times 354.36712963}{228}=365.246822206$ days $=365$ days 05 hours 55 minutes $25.44 \mathrm{sec}$., a big figure indeed, about 7 minutes longer than the modern approximation of average tropical solar year which is about 365.2422 days.

As per Gregorian calendar, length of tropical solar year

$$
\begin{aligned}
& =\frac{(400 \times 365)+100-3}{400} \\
& =365.2425 \text { days }
\end{aligned}
$$

So, theoretically as per Hebrew calendar solar year is 365.246822206 $365.2425=0.00432220597$ days greater than the Gregorian Calendar.

\section{The Main Hypothesis}

2053 solar years $=2116$ lunar years (May be termed as ideal luni-solar cycle) where, $2053=228 \times 9+1,2116=235 \times 9+1$

And,

$$
\begin{aligned}
01 \text { Lunar year } & =354+\left(\frac{1}{3}+\frac{1}{30}+\frac{1}{900}\right)=354+\frac{331}{900}=354.367 \text { days } \\
& =354 \text { days } 08 \text { hours } 49 \text { minutes and } 36 \text { seconds }
\end{aligned}
$$

01 synodic lunar month $=354.36 \dot{7} \div 12=29.5306 \dot{4} 81$ days

$$
\begin{aligned}
& =29.5 \text { days }+\frac{2648}{86400} \text { days } \\
& =29.5 \text { days }+2648 \mathrm{sec} \\
& =29.5 \text { days } 44 \text { minutes } 08 \mathrm{sec}
\end{aligned}
$$

(Proposed new Molad)

Difference between New proposed Molad and existing Hebrew Molad

$$
\begin{aligned}
& =29.5306481 \text { days }-29.5305941358 \text { days } \\
& =(29.5 \text { days }+2648 \mathrm{sec})-\left(29.5 \text { days }+\left(793 \times 3 \frac{1}{3}\right) \mathrm{sec}\right) \\
& =2648 \mathrm{sec}-2643 \frac{1}{3} \mathrm{sec} \\
& =4 \frac{2}{3} \mathrm{sec}
\end{aligned}
$$

Thus, this proposed Molad ( 29.5306481 days) is $4 \frac{2}{3}$ sec. greater than the Hebrew Molad.

This is the basic basis of my hypothesis towards formulation of a well accepted ideal luni-solar calendar in replacement or correction to the existing Hebrew calendar.

However, the length of the mean synodic lunar month varies by up to \pm 0.7 days, because the Moon's orbit is elliptical and the orbit's shape precesses (8.85 yrs) and the orbital plane wobbles (18.6 yrs). But the mean value of lunar synodic month is constant over a long period of time [7] and is a crucial value in determining the Hebrew calendar's "Rashei Hodesh", or New Months. 


$$
\begin{aligned}
01 \text { solar year } & =\frac{354 \frac{331}{900} \times 2116}{2053}=365 \frac{111874}{225 \times 2053} \text { days } \\
& =365 \frac{111874}{461925} \text { days }=365.242190831845 \text { days } \\
& =365 \text { days } 05 \text { hours } 48 \text { minutes } 45 \frac{591}{2053} \mathrm{sec} \\
& =365 \text { days } 05 \text { hours } 48 \text { minutes } 45.2878714077 \mathrm{sec}
\end{aligned}
$$

Mind that, mean length of tropical solar year at J2000 is 365.242190402 ephemeris days [8]; each ephemeris day lasting 86,400 SI seconds. (very close to my calculated one).

$$
\text { Again, } 365.246822206 \text { days }-365 \frac{111874}{461925} \text { days }=0.0046313742 \text { days . }
$$

So, calculated length of Solar year of existing Hebrew calendar is 0.0046313742 days bigger than my calculation and 0.004632206 days greater than the recent well established astronomical value (365.24219 days).

Ancient Syrian Arab astronomer and mathematician, the greatest and the best known astronomer of the medieval Islamic world Al-Battānī (c. 858 - 929CE) worked on Ptolemy's books and corrected some errors related to the length of the year and other situations. He corrected length of solar year proposed by Ptolemy (365 days, 5 hours, 55 minutes, and 12 seconds) in his book Kitāb az-Zīj as 365 days, 5 hours, 46 minutes, and 24 seconds [9], which is only 2 minutes and 22 seconds off from our modern approximation having the value 365.2422 days and 2 minutes and $21 \frac{591}{2053}$ seconds off from my proposed length of solar year having the value 365.242190831845 days.

Another observation regarding co-relation between lunar year and solar year (co-relation having a common fraction) may be expressed as below:

$$
\frac{2116}{Y+1+X}=\frac{2053}{Y+X}
$$

where " $Y$ " is an integer number and " $X$ " is a fractional/decimal number.

Now by trial and error method (iteration) we find that for $Y>32, X$ becomes negative and for $Y<32, X$ becomes greater than one.

Thus, it is nothing but only the integer number 32 (i.e. $Y=32$ ) for which " $X$ " has a positive fractional value and the above equation looks like below:

$$
\begin{aligned}
\frac{2116}{33+X} & =\frac{2053}{32+X} \\
2116(32+X) & =2053(33+X) \\
\text { or, }(2116-2053) X= & 2053 \times 33-2116 \times 32 \\
\text { or, } X=\frac{37}{63} & =0.58730 \dot{1}
\end{aligned}
$$

Thus, the equation finally becomes, $\frac{2116}{33.5 \dot{8} 8730 \dot{1}}=\frac{2053}{32.58730 \dot{1}}$. 
We have, 01 lunar year $=29.53064 \dot{4} 1 \times 12=354.367$ days.

So, alternatively, exact value for tropical solar year in days may be written as below:

$$
\begin{aligned}
354 \frac{331}{900} \times \frac{33 \frac{37}{63}}{32 \frac{37}{63}} & =\frac{318931 \times 2116}{900 \times 2053}=\frac{318931 \times 529}{225 \times 2053}=365 \frac{111874}{461925} \text { days } \\
& =365.24219083184499648211289711 \cdots \\
& \cong 365.242190831845 \text { days } \\
& =365 \text { days } 05 \text { hours } 48 \text { minutes } 45 \frac{591}{2053} \text { seconds }
\end{aligned}
$$

Therefore, it is clear why 2053 solar years (2116 lunar years) should be considered as one epoch. As because the denominator is 2053, which is a prime number, fraction of a second could only be avoided for a 2053 times rotation of the Earth around the Sun.

Thus, 01 epoch $=2053$ years $=\frac{3189.31 \times 2116}{9 \times 2053} \times 2053=\frac{318931 \times 2116}{900}$ days $=749842 \frac{196}{900}$ days $=749842$ days 05 hours 13 minutes 36 sec. (Total $64786367616 \mathrm{sec}$.)

On the other hand, for my proposed luni-solar cycle only after 900 lunar years we will have integer number of days, i.e., $354 \frac{331}{900} \times 900=318931$ days and only after 461,925 solar years we will have integer number of days, i.e.,

$$
\begin{aligned}
& 365 \frac{111874}{461925} \times 461925=168613812 \text { days. } \\
& \text { Again, } 900 \text { lunar years }=\frac{900 \times 2053}{2116}=\frac{225 \times 2053}{529} \text { solar years }
\end{aligned}
$$

Or, $900 \times 529$ lunar years $=225 \times 2053$ solar years.

Or, 476,100 lunar years $=461,925$ solar years $=168,714,499$ days, before which integer no. of days for both lunar and solar years is not possible simultaneously.

However, similar calculation for existing Metonic cycle based lunar-solar co-relation of the Hebrew calendar looks like below:

$$
32+X=\frac{228}{235-228}=32+\frac{4}{7}
$$

Or, $X=\frac{4}{7}$, which is smaller than my calculated fraction by $\frac{37}{63}-\frac{4}{7}=\frac{1}{63}$.

Thus lunar-solar co-relation for Hebrew calendar becomes-

$$
\frac{228}{32+\frac{4}{7}}=\frac{235}{33+\frac{4}{7}}
$$

and for my proposed new lunar-solar co-relation, this becomes-

$$
\frac{2053}{32+\frac{37}{63}}=\frac{2116}{33+\frac{37}{63}}
$$




$$
\frac{365.242190831845}{29.5306 \dot{4} 8 \dot{1}}=\frac{12 \times 2116}{2053}(\text { exactly })=12 \frac{756}{2053}
$$

where as, in case of Hebrew calendar-

$$
\begin{aligned}
& \frac{365.246822206}{29.5305941358}=\frac{12 \times 235}{228}(\text { exactly })=12 \frac{7}{19} \text {, which is bigger to that above by } \\
& \frac{7}{39007} \text {. }
\end{aligned}
$$

So, Hebrew calendar adopts 07 intercalary months in 19 years, usually for $3^{\text {rd }}$, $6^{\text {th }}, 8^{\text {th }}, 11^{\text {th }}, 14^{\text {th }}, 17^{\text {th }}$ and $19^{\text {th }}$ year.

This indicates that theoretically Hebrew calendar will incur an error of one month in $39007 \div 7 \cong 5573$ solar years. In other words, a new year will start 01 month later after 5573 years from the inception of the luni-solar calendar.

In ancient Babylonian culture the value for "precession of equinoxes" was considered as 25,920 years, often referred to as "astronomical age". As the Hebrew calendar founders were primarily heavily influenced by the Babylonian ideas and thoughts, they tried to co-relate one day with this figure " 25920 " by introducing a term called "halaqim", as stated below:

$$
1 \text { day }=243,600=86,400 \text { seconds }=25,920 \text { halaqims }\left(1 \text { halaqim }=3 \frac{1}{3} \text { sec. }\right)
$$

Mind that, 25920 is divisible by all numbers from 1 to 9 except 7 but the next number 25921 is divisible by 7 . Let us prefer the number 25921 instead of 25920 , although it does matter very little in terms of accuracy.

Now it is interesting to notice that the number " 2116 " has also a fair correlation with the Babylonian number 25920 (actually 25921) as depicted below:

- Both the numbers has an integer square root value, 161 and 46 respectively.

- $4 \times 25921=49 \times 2116$.

- Both the numbers has a common factor $529\left(23^{2}\right)$.

- Clear reference exists in the Jews Holy Scriptures for the figure "2116" as well.

\section{A Model for Addition of Intercalary Months of the Proposed Luni-Solar Calendar}

In Hebrew calendar 07 intercalary months are added in 19 years, though detailed considerations about Leap year/Intercalary month of Hebrew calendar are more complicated. Now, how many days have to be allocated for these intercalary months is another issue to be settled down? Mind that Hebrew calendar considers all intercalary months having 30 days.

In this case, let us assume that intercalary months should be applied alternatively as $29 \& 30$ days respectively.

$$
\text { Therefore, } \frac{756 \times 354 \frac{331}{900}}{12 \times 29.5}=756 \text { months } 23.17 \text { days }
$$

So, to keep the luni-solar calendar in right track, we should add 756 interca- 
lary months having 29 and 30 days alternatively, except every 33rd intercalary month. Every $33^{\text {rd }}$ intercalary month should be of 30 days instead of 29 and also 01 extra day should be added to the last $2053^{\text {rd }}$ year to absorb this extra 23 days.

A plan should also be devised to complete adding up of these 756 intercalary months in 2052 years as below:

After every 03 years we should add 01 intercalary month, which will cover $2052 \div 3=684$ months.

Rest $752-786=72$ months

Again, $(2052 \times 2) / 57=72$

So, in addition 02 intercalary months for every 57 years $(01$ month for the first 28 years and another month for the next 29 years) should also be added.

However, apart from complicacy of the detailed intercalary management of luni-solar calendar this is a simple brief outline only.

\section{Inspiration for the Proposed New Luni-Solar Cycle Found in Religious Scriptures}

It is very interesting to note that long before the Jew's religious scriptures had already indicated 2116 years as an epoch /era (standard time span). Mind that usually Biblical scholars considered Biblical "year" narrations as a flat 360 days year or solar year rather than lunar year. Besides, though not directly but an indirect link/clue to this very figure " 2116 " is also observed in the holy Quran i.e., to say otherwise, total number of verses in the holy Quran is 6348, which is 03 times " 2116 ". These instances also urged us to think positively that 2116-2053 years luni-solar cycle instead of conventional 235 - 228 months Metonic cycle is a perfect match to the problem of synchronization to the luni-solar calendar. So let us explore a little bit more to the issue as below:

According to Talmud narration-

"The Tanna debe Eliyyahu taught: The world is to exist six thousand years; the first two thousand years are to be void; the next two thousand years are the period of the Torah, and the following two thousand years are the period of the Messiah."[10].

On the other hand, time span between creation of Adam to emergence of Messiah is stated as 4232 years in Talmud [10], which is simply a summation of two " 2116 ".

However, "emergence of Messiah" and "Creation of Adam" are not our focus at this moment; we just want to talk about the significance of " 2116 " years i.e., it is designated as a "standard time period" by the religious scriptures as well. Let's just simply overlook such issues of the Talmudic expression now.

Biblical scholars knew that this statement of six thousand years is a rough estimate; it would be " $6000+$ some fraction of 1000 years". But what is the exact value of the fraction is a long debated issue. Some say 160 years, some say 480 years and so on.

But if we juxtapose two references 9a \& 9b of "Talmud, Mas. Avodah Zarah", 
it will become clear that these biblical roughly 6000 years is nothing but $3 \times 2116$ $=6348$ years, which I prescribed as lunar one (6159 solar years).

Actually, total no. of verses in the holy Quran is 6236 (without counting opening "Bismillah" verse). Though some difference of opinion persists, majority of Muslim scholars are of the view that the opening verse "Bismillah" of every chapter of the holy Quran is also part and parcel of the holy Quran and so should be counted as the verses of the holy Quran. There are 114 Suras (Chapters) in the Holy Quran. As because Allah declared the no. of verses of the $1^{\text {st }}$ Sura (Sura Fatiha) as 07 (Al-Quran, 15:87), so all groups of Muslims consider it as 07 (irrespective of including or excluding "bismillah"). The $9^{\text {th }}$ Sura has no opening verse "Bismillah" at all at the beginning. So altogether $114-2=112$ should be added to 6236 .

Therefore, total no. of verses in the holy Quran are $6236+112=6348$.

$$
6348=2116 \times 3 \text { (three epoches) }
$$

Is it merely a coincidence or something significant?

However, the Quranic verse as stated below worked as a background inspiration to develop an Urfi/Hizri calendar, assuming 300 solar years equal 309 lunar years but seems unacceptable having a far deviated mean lunar year of 354.6040676699 days (Urfi Molad $=29.53055556$ days) [11].

"Some say they (few monotheist youths of ancient 'Kahf people) stayed in their cave three hundred years and some add another nine." (Al-Quran: 18:25)

Actually, here the verse simply described the then calendar practice nothing else.

\section{Analysis}

According to David Bleich, Dr. Hugo Mandelbaum has stated that an exact lunar-solar cycle is not possible. In other words, a fixed calendar to have repeatability in lunar months relative to the solar year would have an extremely long cycle. He says it would be 689,272 years long [4]. But this study showed that within a time cycle of 2053 solar years an optimum approximation could be achieved.

$\frac{235 \times 12}{228}=12 \frac{7}{19}$, thus, 07 intercalary months is estimated for Hebrew calendar for 19 solar years.

So, Hebrew calendar adds $07 \times 108=756$ intercalary months in $19 \times 108=$ 2052 solar years.

On the other side in case of this hypothetical luni-solar calendar, $\frac{2116 \times 12}{2053}=12 \frac{756}{2053}$

Thus, 756 intercalary months are required to match our proposed ideal luni-solar calendar in 2053 solar years.

This estimate of total intercalary month in 2053 years may also be found as below: 


$$
(2116 \times 12)-(2053 \times 12)=756 \text { months }
$$

In a nutshell, theoretically in case of existing Hebrew calendar 756 intercalary months would be spent by 2052 years against a standard 2053 years ( 01 year before).

We know, lunar year lags behind solar year by

$$
365 \frac{111874}{461925}-354 \frac{331}{900}=10 \frac{179517}{205300} \text { days }=10.8744130541=11 \text { days (approx.) }
$$

Thus, this is an indication that Hebrew calendar will become imbalanced by 11 days after 2053 years from its inception.

Also Mr. Melech Ben Ya'aqov's article pointed out that in Hebrew calendar Sukkot now fall on an average 13 days later than the makers of the calendar seem to have intended [1].

\section{Reflections}

The reflections from the hypothesis may be summarized as below:

1) Formulation of a deviation free high precession luni-solar calendar could be achieved through the application of newly proposed hypothetical 2116-2053 years luni-solar cycle instead of the conventional 235 - 228 months Metonic cycle. Through the application of the proposed new cycle both sides of the luni-solar calendar would become fully harmonized.

2) Recent well accepted astronomical value for the length of "Mean Tropical Solar Year" of 365.24219 days is correct, as finding of this hypothesis is more or less the same i.e. 365.242190831845 days (365 days 05 hours 48 minutes $45 \frac{591}{2053}$ sec).

3) According to this hypothesis Length of "Mean Synodic Lunar Month" i.e. Molad of Hebrew calendar (29.5305941358 days/29.5 days $44 \mathrm{~min} .3 \frac{1}{3} \mathrm{sec}$.) need to be further fine tuned. The proposed value of the Molad is 29.530648i days ( 29.5 days 44 minutes $08 \mathrm{sec}$.), which is $4 \frac{2}{3} \mathrm{sec}$. greater than the present Hebrew Molad.

4) The problem of getting value for length of the tropical solar year in higher side (365.2468222059 days) in Hebrew calendar can be successfully eliminated through the application of the newly proposed Molad of 29.5306481 days and the new 2116-2053 years luni-solar cycle.

\section{Conflicts of Interest}

The author declares no conflicts of interest regarding the publication of this paper.

\section{References}

[1] Ya’Aqov, M.B. (2021) Jewish Calendar Is Slowly Drifting Off Track. "Your Jerusalem", 26 March 2021. 
https://yourjerusalem.org/2010/02/jewish-calendar-is-slowly-drifting-off-track/

[2] Espenak, F. (n.d.) Astropixel's Six Millennium Catalog of Phases of the Moon, Moon Phases from -1999 to +4000 (2000 BCE to 4000 CE).

http://astropixels.com/ephemeris/phasescat/phasescat.html

[3] Aslaksen, H. (n.d.) Heavenly Mathematics: The Mathematics of the Chinese, Indian, Islamic and Gregorian Calendars. Department of Mathematics, National University of Singapore.

https://mathcircle.berkeley.edu/sites/default/files/BMC6/ps0405/calendar-talk-pictu res.pdf

[4] Schloss, H.S. (2000) Accuracy of the Hebrew Calendar. International Journal of Computers and Mathematics with Applications, 39, 23-24.

[5] Sachau, C.E. (1879) The Chronology of Ancient Nations. An English Version of the Arabic Text of the "Athar-ul Bakiya" of Al-Biruni or "Vestiges of the Past," Collected and Reduced to Writing by the Author in A.H. 390-1, A.D. 1000. Translated and Edited, with Notes and Index, by Dr. C. Edward Sachau, Professor in the Royal University of Berlin. London: Published for the Oriental Translation Fund of Great Britain and Ireland by W. H. Allen \& Co., Waterloo Place, Publishers to the India Office, 386.

https://rarebooksocietyofindia.org/book archive/196174216674 1015515680015167 5.pdf

[6] NASA Goddard Media Studios. https://svs.gsfc.nasa.gov/12739

[7] Mendez, B. (n.d.) How Long Is a Year? https://multiverse.ssl.berkeley.edu/Portals/0/CalendarInTheSky/Resources/Presenta tions/HowLongIsAYear.pdf?ver=2013-02-01-165808-543

[8] Wikipedia (n.d.) Sidereal Year. https://en.wikipedia.org/wiki/Sidereal year

[9] Abdullatif, M. (2011) Al-Battani Contributions in Astronomy and Mathematics. IIUM Press, International Islamic University Malaysia. https://www.researchgate.net/publication/260877427

[10] Talmud-Mas. Avodah Zarah 9a \& 9b. https://juchre.org/talmud/zarah/zarah1.htm\#9a

[11] Raharto, M. and Sopwan, N. (2015) A Study the Length of Synodic Periods of Several Lunar Calendar in Indonesia. Astronomi dalam Budaya Nusantara, Astronomical Observatory and Science Center in Sumatera, May 2015, 3. 